\title{
Conservative Surgical Treatment of A Complete Fracture of Pancreatic Isthmus
}

Y.Z.A. Khedid", M. Maliki-Alaoui, M. El Absi, M. Elounani, M. Echarrab, H. El Alami El Faricha, M. Amraoui, A. Errougani

Department of Visceral Surgical Emergencies, Ibn Sina Hospital, Faculty of Medicine and Pharmacy, Mohammed V University, Rabat, Morocco

DOI: $10.36347 /$ sasjs.2020.v06i09.001

| Received: 22.08.2020 | Accepted: 01.09.2020 | Published: 04.09.2020

*Corresponding author: Y.Z.A. Khedid

Abstract

Case Report

Pancreatic trauma is rare, but can cause serious complications, including death. Because of its anatomical situation, the pancreas is usually affected in severe trauma. We present a case report of an 18 year old patient who had a trauma at the level of the right hypochondrium and the epigastrium. Abdominal ultrasound revealed a peritoneal effusion, and the CT-scan showed a pancreatic fracture without pneumoperitoneum. Urgent laparotomy confirmed the isthmic fracture with Wirsung's duct complete section. Treatment consisted in suturing the cephalic part and anastomosis of the pancreatic tail on a Roux-type "Y" jejunal loop. Outcomes were simple. Many studies showed that this procedure is very useful to spare the parenchyma and helps prevent diabetes, if the diagnosis and the surgical treatment are performed quickly.

Keywords: Pancreatic trauma, duodeno-pancreatic trauma, abdominal trauma, exploratory laparotomy, Endoscopic retrograde cholangiopancreatography, pancreaticojejunal anastomosis.

Copyright @ 2020: This is an open-access article distributed under the terms of the Creative Commons Attribution license which permits unrestricted use, distribution, and reproduction in any medium for non-commercial use (NonCommercial, or CC-BY-NC) provided the original author and source are credited.

\section{INTRODUCTION}

Isolated Trauma of the pancreas are rare and serious, representing $1 \%$ to $12 \%$ depending on different series. Their frequency has increased in recent years, due to the increase in the frequency of traffic accidents and assaults. Emergency laparotomy is indicated whenever there is suspicion of a pancreatic duct rupture, the only way to reduce mortality and improve the prognosis of these injuries.

\section{CASE REPORT}

An 18-year-old single patient, a builder by profession, was admitted to the emergency room for an abdominal contusion secondary to trauma by an iron stick with the point of impact at the level of the right hypochondrium and the epigastrium. The patient reported some vomiting without transit disorder, and his general condition was normal. The clinical examination showed a transfixing abdominal pain, the rectal examination was normal. Lipase value was elevated to 1200 IU/ L. The unprepared abdominal x-ray was normal. The abdominal ultrasound revealed a thin section of effusion at the level of the Morrison space, the spleno-renal space and the right iliac fossa.
Emergency abdominal CT scan (figure 1) diagnosed a pancreatic fracture with moderate intraperitoneal effusion without pneumoperitoneum. The urgent laparotomy confirmed the complete isthmic fracture with section of the Wirsung's duct without cytosteatonecrosis (figure 2 and 3). Treatment consisted of suturing the proximal Wirsung canal and anastomosis of the distal Wirsung canal and pancreatic tail on a Roux-type "Y" jejunal loop (figure4). The postoperative recovery was simple.

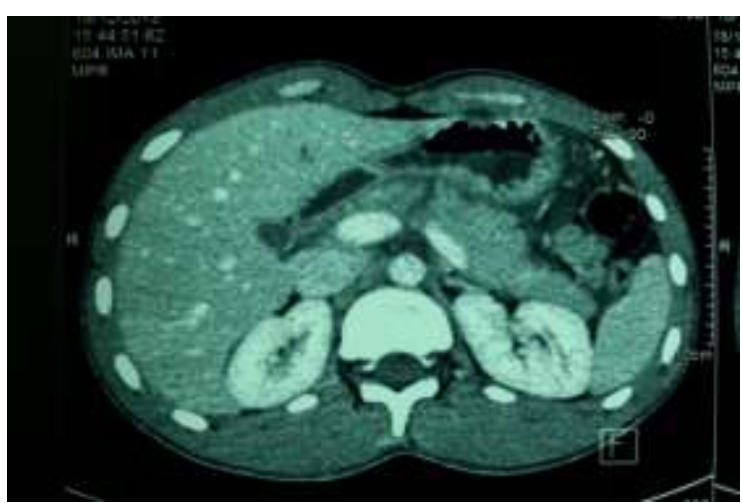

Fig-1: Abdominal CT scan showing complete fracture of the pancreatic isthmus 
Y.Z.A. Khedid et al., SAS J Surg, September, 2020; 6(9): 310-312

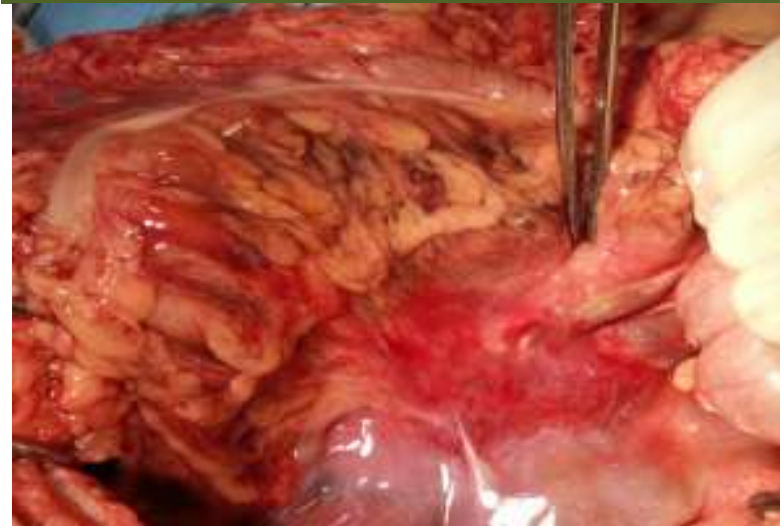

Fig-2: Central retroperitoneal hematoma suggesting a pancreatic lesion

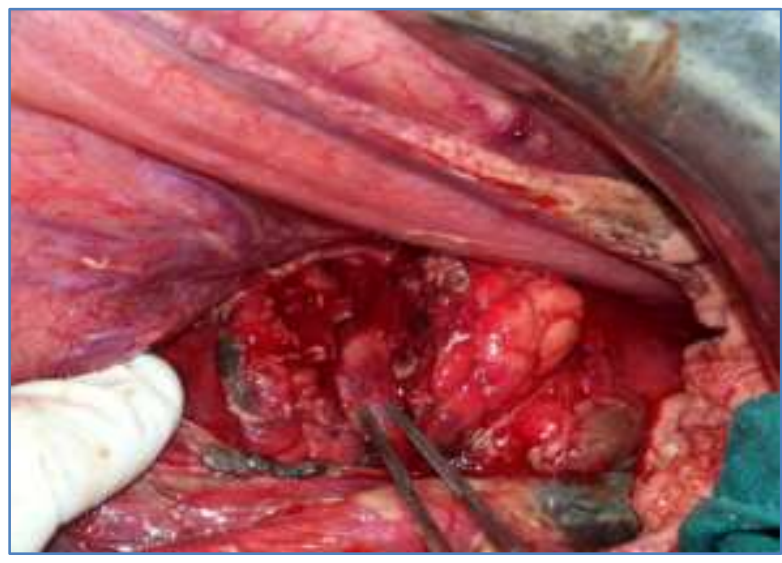

Fig-3: Complete fracture of the pancreas (isthmus) with view of the superior mesenteric vein

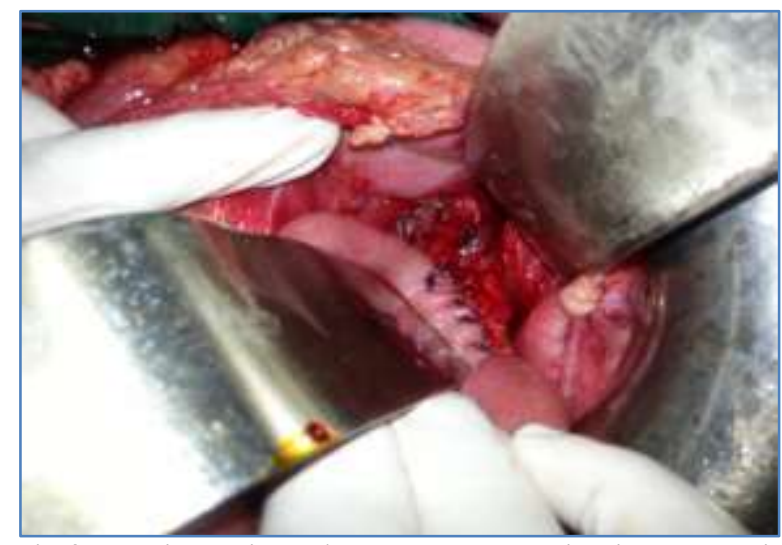

Fig-4: The distal Wirsung's duct and pancreatic tail anastomosis on a Roux-type "Y" loop

\section{DISCUSSION}

In this work, we report the case of a patient successfully treated for isolated pancreatic trauma by closure of the proximal pancreas and pancreatic-jejunal anastomosis on the distal slice.

In case of pancreatic trauma with ductal rupture, several attitudes have been described $[1,2]$. In centers with an appropriate technical platform, the placement of a ductal stent by endoscopic retrograde catheterization can ensure healing [3]. Elsewhere, the treatment is surgical; lot of authors recommend performing a left pancreatectomy (LP) while preserving the spleen [4]. However, LP runs the risk of diabetes and does not always allow splenic preservation[5].

Other authors have proposed direct repair of the fracture by a pancreatico-pancreatic anastomosis, provided that the suture can be performed easily and without tension. In 1959, Letton and Wilson [6] reported two cases of traumatic rupture of the pancreatic isthmus treated by suturing the cephalic part and anastomosis of the pancreatic tail in a jejunal $\mathrm{Y}$ loop.

This technique, described under the term median pancreatectomy (MP), allows to spare the maximum of parenchyma and was then proposed for the excision of benign or low malignancy mediopancreatic tumors not suitable for enucleation. MP, rarely used in pancreatic trauma, aims to preserve the distal parenchyma and consequently to reduce the risk of pancreatic endocrine insufficiency.

After LP, the risk of exocrine pancreatic insufficiency is almost zero, while the rate of occurrence of diabetes is between 2 and $10 \%$ [7-9], compared to $0-2 \%$ in the MP series [5-10]. Pancreatic leak (fistula) after LP is a common cause of morbidity [11]. The mortality of the two interventions is similar in the different published series: $1 \%$ for LP, and $0.7 \%$ for MP.

However, performing this anastomosis certainly requires the absence of necrotizing pancreatitis and a relatively early diagnosis. Otherwise, mortality can be very high [12]. Poor outcome was mostly due to delay in the diagnosis and associated intra-abdominal injuries $[1,13]$.

\section{CONCLUSION}

Isolated pancreatic trauma is rare and may be unrecognized. Clinical examination and biology contribute a little, the gold standard remains the abdominal CT scan and the ERCP. A specific study of the pancreatic ductal status is decisive for the treatment decision. If in doubt, an early exploratory laparotomy of the entire peritoneal cavity and duodeno-pancreatic block is required, which have good results if performed without delay.

\section{REFERENCES}

1. Errougani A, Ameur A, Chkoff R, el Alj A, Balafrej S. Les traumatismes duodénopancréatiques. À propos de 30 observations. J Chir. 1997; 134: 9-13

2. Girard E, Abba J, Cristiano N, Siebert M, Barbois $\mathrm{S}$, Létoublon C, Arvieux C. Management of splenic and pancreatic trauma. J Visc Surg. 2016 Aug;153(4 Suppl):45-60.

3. R Delcenserie, J Ricard, T Yzet, L Rebibo, J-M Regimbeau. Conservative endoscopic management 
Y.Z.A. Khedid et al., SAS J Surg, September, 2020; 6(9): 310-312

for pancreatic. J Visc Surg. 2016 Nov;153(5):391394.

4. Schellenberg $\mathrm{M}$, Inaba $\mathrm{K}$, Cheng $\mathrm{V}$, Bardes JM, Lam L, Benjamin E, Matsushima K, Demetriades D. Spleen-preserving distal pancreatectomy in trauma. J Trauma Acute Care Surg. 2018 Jan;84(1):118-122.

5. Sauvanet A. L'insuffisance exocrine et endocrine est-elle inéluctable après chirurgie pancréatique ? Rev Med Suisse. 2002; 2: 22420.

6. H Letton A, Wilson JP. Traumatic severance of pancreas treated by Roux-Y anastomosis. Surg Gynecol Obstet. 1959 Oct;109:473-478.

7. Cogbill TH, Moore EE, Morris JA. Distal pancreatectomy for trauma: A multicenter experience. J Trauma 1991; 31: 1600-6.

8. Fabre JM, Houry S, Manderscheid JC. Surgery for left sided pancreatic cancer. Br J Surg. 1996; 83:1065-70.
9. Gruessner RWG, Kendall DM, Drangstveit MB. Simultaneous pancreas-kidney transplantation from live donors. Ann Surg. 1997; 226: 471-82.

10. Adams DB, Ford MC, Anderson MC. Outcome after lateral pancreaticojejunostomy for chronic pancreatitis. Ann Surg. 1994; 219: 481-9.

11. J E J Krige, U K Kotze, A J Nicol, P H Navsaria. Morbidity and mortality after distal pancreatectomy for trauma: a critical appraisal of 107 consecutive patients undergoing resection at a Level 1 Trauma Centre. Injury, sept. 2014, 45(9): 1401-1408.

12. Ohanet H, Fasano JJ, Marmuse JP, Fichelle A, Saint-Marc O, Benhamou G. Traumatismes du pancréas: urgence diagnostique et thérapeutique. À propos de 35 cas. J Chir. 1991; 128: 337-342.

13. Farrell RJ, Krige JE, Bornman PC, Knottenbelt JD, Terblanche J. Operative strategies in pancreatic trauma. Br J Surg. 1996; 83: 934-937. 